\title{
1 Reduction in Toxicity of Coking Wastewater to Aquatic 2 Organisms by Vertical Tubular Biological Reactor
}

3 Siyun Zhou ${ }^{\mathrm{a}}$, Haruna Watanabe ${ }^{\mathrm{b}}$, Chang $\mathrm{Wei}^{\mathrm{a}}$, Dongzhou Wang ${ }^{\mathrm{a}}$, Jiti Zhou ${ }^{\mathrm{a}}$, Norihisa

4 Tatarazako ${ }^{\mathrm{b}}$, Shigeki Masunaga ${ }^{\mathrm{c}}$, Ying Zhang ${ }^{\mathrm{a} *}$

5 a Laboratory of Industrial Ecology and Environmental Engineering (MOE), School of Environmental Science and

6 Technology, Dalian University of Technology, Dalian 116024, China

$7{ }^{\mathrm{b}}$ National Institute for Environmental Studies, Endocrine Disrupters and Dioxin Research Project, 162 Onogawa, Tsukuba,

$8 \quad$ Ibaraki 3048506, Japan

$9{ }^{\mathrm{c}}$ Faculty of Environment and Information Sciences, Yokohama National University, 797 Tokiwadai, Hodogaya-ku,

10 Yokohama, Kanagawa 240 8501, Japan

\section{Abstract}

12 We conducted a battery of toxicity tests using photo bacterium, algae, crustacean and fish

13 to evaluate acute toxicity profile of coking wastewater, and to evaluate the performance of a

14 novel wastewater treatment process, vertical tubular biological reactor (VTBR), in the

15 removal of toxicity and certain chemical pollutants. A laboratory scale VTBR system was set

16 up to treat industrial coking wastewater, and investigated both chemicals removal efficiency

17 and acute bio-toxicity to aquatic organisms. The results showed that chemical oxygen

18 demand (COD) and phenol reductions by VTBR were approximately 93\% and 100\%,

19 respectively. VTBR also reduced the acute toxicity of coking wastewater significantly:

20 Toxicity Unit (TU) decreased from 21.2 to 0.4 for Photobacterium phosphoreum, from 9.5 to

* Corresponding author. Tel.: +86-411-84708929; Fax: +86-411-84706252.

E-mail address: yzhang@dlut.edu.cn

(C) 2015. This manuscript version is made available under the Elsevier user license http://www.elsevier.com/open-access/userlicense/1.0/ 
210.6 for Isochrysis galbana, from 31.9 to 1.3 for Daphnia magna, and from 30.0 to nearly 0

22 for Danio rerio. VTBR is an efficient treatment method for the removal of chemical

23 pollutants and acute bio-toxicity from coking wastewater.

24 Keywords: acute toxicity; bio-toxicity; Daphnia; phenol removal; toxicity removal; toxicity

25 unit (TU)

26 


\section{Introduction}

28 China is one of the largest coke producer of coke in the world, e.g. nearly $48 \%$ of total coal

29 production in the world was produced in China in the year of 2012 (BP, 2013). Thus the

30 coking wastewater is a typical industrial wastewater in China. Coking wastewater is

31 composed of high concentrations of organic and inorganic pollutants, e.g. phenols, nitrogen

32 heterocyclic compounds, polycyclic aromatic hydrocarbons, cyanide, sulfide and ammonia

33 nitrogen (Yang et al., 2007; Kim et al., 2008; Lu et al., 2009; Zhang et al., 2012). Most of

34 these compounds are refractory, toxic and carcinogenic, which may pose potential ecological

35 risk to the receiving water bodies (Lai et al., 2007; Zheng et al., 2007).

36 The bio-toxicity of coking wastewater was commonly tested with lux bacteria (Zhao et al.,

37 2009; Ma and Wang, 2013; Zhao et al., 2014), alga (Zhao et al., 2014), invertebrate (Zitova

38 et al., 2009; Zhao et al., 2014), fish and plants (Dong and Zhang, 2010; Han et al., 2011; Wei

39 et al., 2012; Zhao et al., 2014), involving acute toxicity (Zitova et al., 2009; Zhu et al.,

40 2013b; Zhao et al., 2014) or/and genotoxicity (Dong and Zhang, 2010; Han et al., 2011; Zhu

41 et al., 2013a). However, there was only segmental information on the eco-toxicity profile of

42 coking wastewater until now. A battery of toxicity test is demonstrated to be useful to clarify

43 the toxicity profile for complex environmental samples (e.g. Wastewater) using different

44 aquatic test organisms (i.e. bacterium, algae, Daphnia and fish) (Fang et al., 2012; Zhao et al.,

45 2014). Herein, a battery of toxicity test is needed to clarify the toxicity profile of coking 46 wastewater. 
47 Conventional activated sludge (CAS) technology has been widely used in industrial

48 wastewater treatment. However, the refractory and toxic compounds in coking wastewater

49 often inhibit the performance of microorganism in CAS. The effluents from CAS process

50 often do not meet the regulation standards for discharge in China, therefore, modified CAS or

51 some other advanced technology has been developed to remove chemical oxygen demand

52 (COD), ammonia or phenolic compounds further (Zhao et al., 2009; Lu et al., 2010; Yuan et

53 al., 2012; Jin et al., 2013; Wei et al., 2012; Zhao et al., 2014).

54 VTBR is a novel biological treatment technique (China patent: ZL00131550.1,

55 ZL00131325.8 and ZL00131326.6). Based on deep-well process, VTBR integrates some

56 treatment processes, i.e. biofilm reaction, compressed bio-contact oxidation, anaerobic

57 denitrification, aerobic hydrolysis and sludge digestion, into single process with the aid of

58 delicately-selected filler material and well-designed combined reactors. VTBR is

59 characterized by high gas-liquid mass transfer efficiency and efficient oxygen utilization

60 even under high COD load. VTBR has been applied in some kinds of industrial wastewater

61 with good performance in COD and ammonia removal (Xu et al., 2010). However, there is

62 no information on its toxicity removal performance until now.

63 In this study, the whole eco-toxicity profile of industrial coking wastewater was

64 investigated before and after the VTBR process. A battery of acute toxicity test was

65 conducted using lux bacteria (P. phosphoreum), alga (I. galbana), crustacean (D. magna) and

66 fish (D. rerio). Meanwhile, conventional chemical indexes (e.g. COD, volatile phenol) were 
67 also investigated. This study aims to clarify the whole acute toxicity profile of coking

68 wastewater and to evaluate the acute toxicity removal efficiency of VTBR.

\section{Materials and Methods}

\subsection{Wastewater sample}

72 The industrial coking wastewater is the wastewater mixture from different processes in the

73 steelwork, e.g. ammonia distillation, gas purification and/or recycles process. Our sample

74 was collected from a typical steelwork in April, 2012 in Dalian, China. The water quality

75 parameters of influent to VTBR were shown in Table 1. No additional nitrogen and

76 phosphorus was added during the treatment process since the existing $\mathrm{NH}_{3}-\mathrm{N}$ and phosphorus

77 in the wastewater were enough for the growth of micro-organisms.

\subsection{Operation condition of VTBR}

79 Laboratory scale VTBR (Fig. 1) was set up with three poly-methyl methacrylate columns

80 (6 L) in series, filled with the elastic fibrous filler that enhance the volume of

81 microorganisms. It can be seen that aeration was flowed to the VTBR from the first column

82 only; therefore, the gas went through the vertical baffle in the same direction of the liquid

83 inside the whole VTBR process. Microorganisms within active sludge grew well around the

84 filler columns, where aerobic species dominated in the outside layer, anoxic species

85 presented in the medium layer and anaerobic species dominated in the inner layer.

86 The operational conditions were as follows: inflow rate was $0.6 \mathrm{~L} \mathrm{~h}^{-1}$, sludge reflux ratio 
87 was $1: 1$, hydraulic retention time was $30 \mathrm{~h}, \mathrm{pH}$ was $7.9 \pm 0.2$, temperature was $21.5 \pm 0.5^{\circ} \mathrm{C}$

88 and the first column was only aerated with air compressor. The activate sludge used to start

89 VTBR was taken from a typical municipal wastewater treatment plant, Chunliuhe wastewater

90 treatment plant, in Dalian, China.

\section{$91 \quad$ 2.3. Chemical analysis}

92 Both influent and effluent water samples were subjected to the following chemical

93 analyses: $\mathrm{COD}$, measured with potassium dichromate titration; $\mathrm{NH}_{3}-\mathrm{N}$, analyzed according to

94 the Nessler's reagent spectrophotometry; total nitrogen (TN), tested by the alkaline potassium

95 persiflage digestion-UV spectrophotometric method; Phenolics, determined according to

96 4-AAP spectrophotometric method; dissolved oxygen (DO), analyzed using portable

97 dissolved oxygen meter (Mettler toledo, USA); $\mathrm{pH}$, determined by $\mathrm{pH}$ meter (Sartorius,

98 Germany); biology oxygen demand (BOD), tested using BOD Trak meter (Hach, USA).

99 Organic substances were detected by gas chromatography-mass spectrometer (GC-MS)

100 (Agilent, USA). The pretreatment of the samples and the GC-MS analysis were performed in

101 accordance with the methods described in Lai et al. (2008).

\section{2.4. Acute bio-toxicity test}

103 Wastewater samples (influent and effluent) were tested with a series of dilution in triplicate

104 unless otherwise specified. The toxicities of the samples $\left(\mathrm{EC}_{50}\right.$ or $\left.\mathrm{LC}_{50}\right)$ were expressed by

105 the dilution factor. 
107 Bioluminescence inhibition test was conducted according to the Luminescent bacteria test

108 procedure (SEPA, 1995). The luminescence of $P$. phosphoreum was detected using Lumin

109 Max-C (Maxwell, USA). The P. phosphoreum was provided by the Institute of Soil Science,

110 Chinese Academy of Sciences, Nanjing, China. The bioluminescence inhibition test was

111 conducted after the $P$. phospherum exposed to the wastewater for 20 minutes. Then the

112 luminescence was then measured after exposure immediately.

\section{2.4.2. Alga growth inhibition test}

114 Alga toxicity was conducted by measuring the growth inhibition of freshwater green alga $I$.

115 galbana according to OECD 201 (2006). Here, I. galbana, friendly provided by Chinese

116 National Marine \& Environment Monitor Center (Dalian, China), was selected to be test

117 microorganism based on our pre-tests results. Our pre-tests showed that I. galbana was the

118 most sensitive algae species to the toxicity of coking wastewater among the four species of

119 microalgae tested (I. galbana, Scenedesmus obliquus, Chlorella pyrenoidosa and Chlorella

120 spp.).

121 2.4.3. Daphnia magna acute immobilization test

122 D. magna $48 \mathrm{~h}$ acute immobilization test was carried out according to the OECD 202

123 (2004) with a few modifications. Exposure experiment was conducted with five neonates

124 (less than $24 \mathrm{~h}$ old) in $50 \mathrm{ml}$ test solution. Here, five test concentration series were conducted

125 with four replicates.

\section{2.4.4. Zebra fish swimming behavior inhibition test}


127 The lethal toxicity to zebra fish was firstly conducted within $96 \mathrm{~h}$ using static method

128 according to ISO (1996) with some modifications. Six healthy zebra fish (length of $35 \pm 5$

$129 \mathrm{~mm}$, weight of $0.3 \pm 0.1 \mathrm{~g}$ ) were put in the same beaker ( $1 \mathrm{~L}$ test solution in $1.5 \mathrm{~L}$ container),

130 containing four dilution series of coking wastewater influent $(2 \%, 3 \%, 5 \%$ and $10 \%)$, and

131 four VTBR effluent $(20 \%, 40 \%, 80 \%$ and $100 \%)$. The concentrations of test solution were

132 assigned on the basis of pre-test results, which conducted with triplicate per concentration.

133 After $24 \mathrm{~h}, 48 \mathrm{~h}$ and $96 \mathrm{~h}$, the lethal rate was recorded.

134 Another acute toxicity tests called "swimming behavior inhibition test" was also

135 performed as described in Kang et al. (2009), using 3D-biosensor developed by Seiko

136 Electric Ltd., Japan. One piece of healthy zebra fish was exposed to test solution for 60 min

137 after pre-exposure with dechlorinated tap water for $30 \mathrm{~min}$ to let the fish adapt to the small

138 size of test chamber. The test solutions were designed as the same concentration as the lethal

139 toxicity test to fish. The swimming behavior of test fish was investigated for total $90 \mathrm{~min}$,

140 whose 3D data ( $\mathrm{x}, \mathrm{y}, \mathrm{z}$ coordinates) were recorded three times per second. Surface behavior

141 was defined as that the vertical position of fish stayed at $20 \mathrm{~mm}$ below the surface in the test

142 chamber $(10 * 10 * 15 \mathrm{~cm})$. The frequency of swimming speed and duration time of surface

143 behavior of test fish were used to reflect the toxicity of test solution. Each concentration of

144 coking wastewater was repeated 8 times. Here, all of the parameters were retrieved from the

145 raw records by 3D-biomonitor and analyzed at consecutive 10 min interval.

\section{$146 \quad 2.5$. Data analysis}


147 Toxicity data was expressed with $\mathrm{EC}_{50}$ (concentration for $50 \%$ of maximal effect) or $\mathrm{LC}_{50}$

148 (lethal concentration 50) values and its 95\% confidence intervals, which were calculated with

149 SPSS 20.0 (IBM, USA). One-way ANOVA was used to check the significant difference (p <

150 0.05) between the toxicity data of the influent and effluent within software SPSS 20.0. The data

151 showed in this study were expressed as mean \pm SD unless otherwise specified.

152 TU approach was also introduced to reflect the acute toxicity, which was expressed as TU

$153=1 / \mathrm{EC}_{50}$. According to the toxicity classification system introduced by Persoone et al. (2003),

154 the toxicity of the effluent was divided into five levels as follows: no acute toxicity: TU $<0.4$;

155 slight acute toxicity: $0.4<\mathrm{TU}<1$; acute toxicity: $1<\mathrm{TU}<10$; high acute toxicity: $10<\mathrm{TU}$

$156<100$; very high acute toxicity: TU > 100 .

\section{3. Results and Discussion}

\section{3.1. Chemicals removal}

\section{3.1.1. COD and phenol removal}

160 VTBR removed $93.0 \pm 3 \%$ of COD, from $1340 \pm 263 \mathrm{mg} \mathrm{L}^{-1}$ in influent to $100 \pm 51 \mathrm{mg}$

$161 \mathrm{~L}^{-1}$ in effluent. The COD of effluent can meet the discharge standard of coking wastewater

162 regulated in China (SEPA, 1996). The phenol in VTBR effluent decreased to $2.70 \pm 0.80 \mathrm{mg}$

$163 \mathrm{~L}^{-1}$ from $605 \pm 128 \mathrm{mg} \mathrm{L}^{-1}$, with the removal of about $100 \%$, but it was still higher than the

164 discharge standard of $0.5 \mathrm{mg} \mathrm{L}^{-1}$ that regulated by GB8978-1996 in China.

165 Studies on coking wastewater treatment using CAS showed that the COD removal 166 efficiency was not as effective or stable as expected (Zhao et al., 2009). Jin et al. (2013) 
167 found that $83 \% \mathrm{COD}$ and $100 \%$ phenol were removed by A/A/O biological treatment. Yuan

168 et al. (2012) concluded COD removal of coking wastewater improved from $69 \%$ to $89 \%$ after

169 pretreating coking wastewater with the extraction replacement method for 5 min using a 1:1

170 ratio of extract agent to wastewater, which followed by biodegradation treatment. It is known

171 that COD and phenol removal efficiency by conventional biological treatment process are

172 heavily dependent on the influent loads. Consequently, the effluent should be further purified

173 by advanced process or combined/modified biological process. Comparatively, VTBR, a

174 novel biological treatment process, can remove more than $90 \%$ COD and $99 \%$ phenol, even

175 under the relatively high COD and phenol influent load, which may be contributed to the

176 high oxygen utilization and the high concentration of mixed liquid suspended solids (MLSS).

177 Therefore, it can be concluded that the performance of VTBR is better than the conventional

178 biological treatment process with or without pretreatment.

$179 \quad$ 3.1.2. Organic compounds removal

180 The organic compounds in coking wastewater were analyzed with GC/MS. The organic

181 compounds detected in the influent and in the effluent are shown in Table 2. The major

182 organic compounds in influent were phenols. Meanwhile, some kinds of phenols in the

183 influent could not be detected in the effluent, while other new compounds were found in the

184 effluent. It illustrated that VTBR can remove most of the organic compounds in the influent,

185 and some new organic compounds presented within VTBR process. This suggested that the

186 toxicity profile may be different between influent and effluent. 


\subsection{Toxicity bioassay}

188 The dilution factor of the influent/effluent was used to express the concentration of test 189 solution. Here, the concentration of $100 \%$ means the test solution (influent or effluent)

190 without dilution.

\section{$191 \quad$ 3.2.1. Microtox test}

192 The luminous intensity inhibition rates for VTBR influent and effluent are shown in Fig.

193 2A. It can be seen that the inhibition rate of luminous bacteria was about $90 \%$ when exposed 194 to $5 \%$ influent and it was only $9 \%$ when exposed to the whole effluent. TU of coking 195 wastewater by VTBR decreased from 21.2 (influent) to 0.4 (effluent). According to the 196 toxicity classification system raised by Persoone et al. (2003), the influent of coking 197 wastewater was classified to be high acute toxicity, while the effluent of VTBR was slight 198 acute toxicity. It can be seen that VTBR could reduce most portion of acute toxicity to

199 luminous bacteria from the coking wastewater. Zhao et al. (2014) evaluated the toxicity of 200 coking wastewater treated by four stages process (anoxic-oxic-hydrolytic-oxic couples with 201 biological fluidized bed) with E. Coli HB 101 pUCD607 for 15-min inhibition, and found 202 that the TU for influent was 16.2 and for effluent was 0. Compared with their 203 four-stage-process, our VTBR can also remove the acute toxicity to luminous bacteria 204 effectively.

\subsubsection{Alga growth inhibition test}

206 After $96 \mathrm{~h}$ exposure, the dose-response curves of influent and effluent on I. galbana are 
207 shown in Fig. 2B. The calculated $96-\mathrm{h} \mathrm{EC}_{50}$ of coking wastewater influent was about $11 \%$,

208 nearly equal to the 96-h TU of 9.5; meanwhile, the 96-h TU of the effluent from VTBR was

209 only 0.6. VTBR could reduce acute toxicity of coking wastewater to alga from acute toxicity

210 level to slight acute toxicity level. Other study (Zhao et al., 2014) showed that their typical

211 biological treatment process cannot remove the acute toxicity to algae with $72 \mathrm{~h}$ inhibition

212 test.

\section{$213 \quad$ 3.2.3. D. magna acute immobilization test}

214 The dose-response curves of D. magna acute immobilization test for the VTBR influent

215 and effluent are shown in Fig. 2C and Fig. 2D. It can be seen that the mean value of 48-h

$216 \mathrm{EC}_{50}$ for the influent was about $3 \%(95 \% \mathrm{CI}: 2.90 \%-3.50 \%)(\mathrm{p}<0.05)$, while the 48-h $\mathrm{EC}_{50}$

217 for the effluent from VTBR were increased to $77 \%(95 \%$ CI: $73.6 \%-80.7 \%)(\mathrm{p}<0.05)$.

218 That is to say, TU (48h) of the influent was about 31.9 and TU (48h) of the effluent was

219 about 1.3. It can be seen that acute toxicity of coking wastewater to D. magna was effectively

220 reduced by VTBR. Although our VTBR were not as effective in acute toxicity removal as

221 that of four-stage-process (anoxic-oxic-hydrolytic-oxic couples with biological fluidized bed)

222 (Zhao et al., 2014), our VTBR was still comparative due to our simple treatment process.

\section{$223 \quad$ 3.2.4. Zebra fish swimming behavior inhibition test}

224 According to the zebra fish $96 \mathrm{~h}$ acute toxicity pre-test exposed to the influent and VTBR 225 effluent, the 96-h $\mathrm{LC}_{50}$ of influent was about $3 \%$ and no fish died after $96 \mathrm{~h}$ exposure to the 226 VTBR effluent. That is to say, the TU of the influent was about 30 and for the effluent was 0. 
228 acute toxicity profile of coking wastewater influent and effluent, by examining the changes

229 of swimming speed and vertical position. The changes of swimming speed of test fish

230 exposed to control, influent and VTBR effluent are shown in Fig.3 (A). When exposed to the

231 control solution, the frequency of swimming speed did not change distinctly within 90

232 minutes, where the most frequent swimming speed was $21-40 \mathrm{~mm} \mathrm{~s}^{-1}$. When exposed to the

233 influent, the swimming speed decreased suddenly and the dominant swimming speed was

234 0-20 $\mathrm{mm} \mathrm{s}^{-1}$ within 90 minutes. Compared with that exposed to the control, it can be seen

235 that the swimming speed hardly changed after exposed to VTBR effluent, whic illustrated

236 that the toxicity of influent to fish was mostly reduced by VTBR.

237 The duration time of surface behavior was also investigated and statistically analyzed

238 (shown in Fig.3 (B)). From Fig.3 (B)), it can be seen the duration time of surface behavior of

239 fish exposed to VTBR effluent was similar to that exposed to the control, while it differed

240 significantly from that exposed to the influent. These results were consistent with the former

241 study that found that the duration time of surfacing behavior increased with the increment of

242 the toxic chemical concentration (Little and Finger, 1990). This suggested that VTBR could

243 reduce most of the toxicity to the fish in the view of surface behavior.

244 Generally, both the swimming speed and the surface behavior changed significantly when

245 the test fish exposed to influent, while there was no obvious changes after exposed to the

246 control and VTBR effluent. This suggested that VTBR could reduce the toxicity of coking 
247 wastewater to the swimming behavior of zebra fish effectively. The swimming behavior

248 inhibition test was first used in the evaluation of toxicity profile for coking wastewater as we

249 know.

$250 \quad 3.2 .5$. Generalization of Toxicity

251 In this study, the acute toxicity profile of coking wastewater was demonstrated with four

252 test organisms: bacteria (Photobacterium phosphoreum), algae (Isochrysis galbana),

253 Crustacean (Daphnia magna) and fish (Danio rerio). The raw industrial coking wastewater

254 presented high toxicity to all these four test species with TU ranging from 9.50 to 31.9. After

255 treatment with our novel process VTBR, the toxicity of the effluent to four test species near

256 zero except to the Daphnia Magna. From the values of TU of four test species to the coking

257 wastewater given in Fig.4, it can be seen that Daphnia magna presented the relatively high

258 sensitivity to the toxicity of coking wastewater influent and effluent. VTBR illustrated the

259 effective performance on the toxicity removal of coking wastewater. Moreover, the

260 swimming behavior inhibition test was also used to evaluate the toxicity profile for coking

261 wastewater, which illustrated that it was more effective than the fish inhibition test,

262 especially to the low toxicity wastewater.

263 4. Conclusions

264 In this study, the performance of VTBR in coking wastewater treatment was evaluated by a

265 battery of bio-toxicity test, as well as chemical analysis. The findings are as follows: VTBR

266 was shown to be effective not only in the reduction of conventional index (COD and phenol), 
but also in the reduction of acute toxicity. Daphnia was found to be the most sensitive test

organism within the selected test organisms to the toxicity of coking wastewater. VTBR can

269 be an alternative for industrial coking wastewater treatment.

270

271 Acknowledgements:

272 It was supported by National Natural Science Foundation of China (NSFC-JST,

273 21261140334), and Open Project of State Key Laboratory of Urban Water Resource and

274 Environment, Harbin Institute of Technology (ESK201408).

\section{Reference}

BP. BP Statistical Review of World Energy June 2013 [EB/OL]. [2013.12.10]. http://222.26.160.150/videoplayer/statistical_review_of_world_energy_2013.pdf.

Dong, Y.R., Zhang, J.T., 2010. Testing the genotoxicity of coking wastewater using Vicia faba and Hordeum vulgare bioassays. Ecotox. Environ. Saf. 73, 944-948.

Fang, Y.X., Ying, G.G., Zhang, L.J., Zhao, J.L., Su, H.C., Yang, B., Liu, S., 2012. Use of TIE techniques to characterize industrial effluents in the Pearl River Delta region. Ecotox. Environ. Saf. 76, 143-152.

Han, M., Li, G.K., Sang, N., Dong, Y.R., 2011. Investigating the bio-toxicity of coking wastewater using Zea mays L. assay. Ecotox. Environ. Saf. 74, 1050-1056.

ISO, 1996. Determination of the acute lethal toxicity of substances to a freshwater fish [Brachydanio rerio Hamilton-Buchanan (Teleostei, Cyprinidae)] (ISO 7346).

Jin, X.W., Li, E.C., Lu, S.G., Qiu, Z.F., Sui, Q., 2013. Coking wastewater treatment for industrial reuse purpose: combining biological processes with ultrafiltration, nanofiltration and reverse osmosis. J. Environ. Sci-China 25, 1565-1574.

Kang, I.J., Moroishi, J., Nakamura, A., Nagafuchi, K., Kim, S.G., Oshima, Y., 2009. Biological monitoring for detection of toxic chemicals in water by the swimming behavior of small freshwater fish. J. Fac. Agr. Kyushu Univ. 54, 209-214.

294 Kim, Y.M., Park, D., Lee, D.S., Park, J.M., 2008. Inhibitory effects of toxic compounds on nitrification process for cokes wastewater treatment. J. Hazard Mater 152, 915-921. 
Lai, P., Zhao, H., Ye, Z., Ni, J., 2008. Assessing the effectiveness of treating coking effluents using anaerobic and aerobic biofilms. Process Biochemistry 43, 229-237.

Lai, P., Zhao, H.Z., Wang, C., Ni, J.R., 2007. Advanced treatment of coking wastewater by coagulation and zero-valent iron processes. J. Hazard Mater 147, 232-239.

Little, E.E., Finger, S.E., 1990. Swimming behavior as an indicator of sublethal toxicity in fish. Environ. Toxicol. Chem. 9, 13-19.

Lu, Y., Wang, Y., Shen, S.F., Yan, L.H., Zhai, S.J., Chen, B.J., Zhang, J.F., Zhou, S.F., 2010. Biodegradation of organic compounds from coking wastewater with UASB reactor. Water Sci. Technol. 62, 1784-1790.

Lu, Y., Yan, L.H., Wang, Y., Zhou, S.F., Fu, J.J., Zhang, J.F., 2009. Biodegradation of phenolic compounds from coking wastewater by immobilized white rot fungus Phanerochaete chrysosporium. J. Hazard Mater 165, 1091-1097.

OECD (Organisation for Economic Cooperation and Development), 2004. Guide-lines for the testing of chemicals, Daphnia sp. Acute Immobilisation Test. OECD Guideline 202. France.

OECD (Organisation for Economic Cooperation and Development), 2006. Guide-lines for the testing of chemicals, freshwater alga and cyanobacteria Growth Inhibition Test. OECD Guideline 201. France.

Persoone, G., Marsalek, B., Blinova, I., Torokne, A., Zarina, D., Manusadzianas, L., Nalecz-Jawecki, G., Tofan, L., Stepanova, N., Tothova, L., Kolar, B., 2003. A practical and user-friendly toxicity classification system with microbiotests for natural waters and wastewaters. Environ. Toxicol. 18, 395-402.

SEPA (State Environmental Protection Administration), 1995. Water quality-Determination of the acute toxicity-Luminescent bacteria test. GB/T 15441-1995. China.

SEPA (State Environmental Protection Administration), 1996. Integrated wastewater discharge standard. GB 8978-1996. China.

Wei, X.X., Zhang, Z.Y., Fan, Q.L., Yuan, X.Y., Guo, D.S., 2012. The effect of treatmentstages on the coking wastewater hazardous compounds and their toxicity. J. Hazard Mater 239, 135-141.

Xu, Y.L., Zhou, J.T., Qu, Y.Y., Yang, H., Liu, Z.J., 2010. Dynamics and oxygen transfer of a novel vertical tubular biological reactor for wastewater treatment. Chem. Eng. J. 156, 92-97.

Yang, M., Sun, Y., Xu, A.H., Lu, X.Y., Du, H.Z., Sun, C.L., Li, C., 2007. Catalytic wet air oxidation of coke-plant wastewater on ruthenium-based eggshell catalysts in a bubbling bed reactor. B. Environ. Contam. Tox. 79, 66-70.

Yuan, X.Y., Sun, H.F., Guo, D.S., 2012. The removal of COD from coking wastewater using extraction replacement-biodegradation coupling. Desalination 289, 45-50.

Zhang, W.H., Wei, C.H., Chai, X.S., He, J.Y., Cai, Y., Ren, M., Yan, B., Peng, P.A., Fu, J.M., 
2012. The behaviors and fate of polycyclic aromatic hydrocarbons (PAHs) in a coking wastewater treatment plant. Chemosphere 88, 174-182.

Zhao, W.T., Huang, X., Lee, D.J., 2009. Enhanced treatment of coke plant wastewater using 337 an anaerobic-anoxic-oxic membrane bioreactor system. Sep. Purif. Technol. 66, 279-286.

338 Zhao, J. L., Jiang, Y. X., Yan, B., Wei, C. H., Zhang, L. J., Ying, G. G. 2014. Multispecies Acute Toxicity Evaluation of Wastewaters from Different Treatment Stages in a Coking Wastewater-Treatment Plant. Environ. Toxicol. Chem. 33(9), 1967-1975.

Zheng, N., Wang, Q.C., Zheng, D.M., 2007. Health risk of $\mathrm{Hg}, \mathrm{Pb}, \mathrm{Cd}, \mathrm{Zn}$, and $\mathrm{Cu}$ to the 343 Environ. 383, 81-89.

344 Zhu, N., Li, H.Y., Li, G.K., Sang, N., 2013a. Coking wastewater increases micronucleus 345 frequency in mouse in vivo via oxidative stress. J. Environ. Sci-China 25, 2123-2129.

346 Zhu, X.B., Chen, L.J., Liu, R., Liu, C., Pan, Z.D., 2013b. Biotoxicity evaluation of coking wastewater treated with different technologies using Japanese medaka (Oryzias latipes). Environ. Sci-Proc. Imp. 15, 1391-1396.

Zitova, A., O'Mahony, F.C., Cross, M., Davenport, J., Papkovsky, D.B., 2009. Toxicological profiling of chemical and environmental samples using panels of test organisms and optical oxygen respirometry. Environ. Toxicol. 24, 116-127. 
Table 1 Chemical parameters of industrial coking wastewater.

\begin{tabular}{ccc}
\hline \multicolumn{3}{c}{ Characterization of influent $(\mathrm{n}=5)$} \\
\hline Chemical parameters & Range & Mean \\
\hline COD $\left(\mathrm{mg} \mathrm{L}^{-1}\right)$ & $893-1790$ & $1340 \pm 263$ \\
$\mathrm{NH}_{4}{ }^{+}\left(\mathrm{mg} \mathrm{L}^{-1}\right)$ & $103-640$ & $372 \pm 194$ \\
Phenol $\left(\mathrm{mg} \mathrm{L}^{-1}\right)$ & $415-792$ & $605 \pm 128$ \\
BOD $\left(\mathrm{mg} \mathrm{L}^{-1}\right)$ & $760-1520$ & $1140 \pm 224$ \\
$\mathrm{TN}\left(\mathrm{mg} \mathrm{L}^{-1}\right)$ & $273-863$ & $572 \pm 251$ \\
$\mathrm{pH}\left(\mathrm{mg} \mathrm{L}^{-1}\right)$ & $7.7-8.1$ & $7.9 \pm 0.2$ \\
$\mathrm{TP}\left(\mathrm{mg} \mathrm{L}^{-1}\right)$ & $10-15$ & - \\
TOC $\left(\mathrm{mg} \mathrm{L}^{-1}\right)$ & $1140-1340$ & $1220 \pm 85$ \\
Temperature $\left.{ }^{\circ} \mathrm{C}\right)$ & $21-22$ & $21.5 \pm 0.7$ \\
\hline
\end{tabular}


Table 2 Organic compounds detected in influent and effluent of VTBR.

\begin{tabular}{|c|c|c|c|c|c|c|c|}
\hline No. & Compounds & Influent & $\begin{array}{c}\text { Efflue } \\
\mathrm{nt}\end{array}$ & No. & Compounds & Influent & Effluent \\
\hline 1 & Phenol & + & - & 15 & $\begin{array}{l}\text { N-Cyclohexyl-1,3-p } \\
\text { ropanediamine }\end{array}$ & - & + \\
\hline 2 & p-Cresol & + & - & 16 & Naphthalene & - & + \\
\hline 3 & m-Cresol & + & - & 17 & $\begin{array}{l}\text { 1-Ethylidene- } \\
\text { 1H-indene }\end{array}$ & - & + \\
\hline 4 & $\begin{array}{c}\text { 2,3-Dimethylphen } \\
\text { ol }\end{array}$ & + & - & 18 & $\begin{array}{c}\text { 1,3-Diazaspiro[4.5]d } \\
\text { ecane-2,4-dione }\end{array}$ & - & + \\
\hline 5 & 2-Ethylphenol & + & - & 19 & $\begin{array}{c}1,1^{\prime} \text {-Sulfonyldibenze } \\
\text { ne }\end{array}$ & - & + \\
\hline 6 & $\begin{array}{c}\text { 2,5-Dimethylphen } \\
\text { ol }\end{array}$ & + & - & 20 & $\begin{array}{l}\text { 4-Isopropyl-1-methy } \\
\text { 1-2-cyclohexen-1-ol }\end{array}$ & - & + \\
\hline 7 & $\begin{array}{c}\text { 3,4-Dimethylphen } \\
\text { ol }\end{array}$ & + & - & 21 & $\begin{array}{l}\text { 2-(Azidomethyl)-1,3 } \\
\text {,3-trimethylcyclohe } \\
\text { xene }\end{array}$ & - & + \\
\hline 8 & $\begin{array}{c}\text { 2,4-Dimethylphen } \\
\text { ol }\end{array}$ & + & - & 22 & $\begin{array}{c}\text { 2-Isopropyl-5-methyl } \\
\text { phenyl } \\
\text { methylcarbamate }\end{array}$ & - & + \\
\hline 9 & $\begin{array}{l}\text { 4-Ethyl-2-methylp } \\
\text { henol }\end{array}$ & + & - & 23 & $\begin{array}{l}\text { 3,3-Dimethyl } \\
\text { piperidine }\end{array}$ & - & + \\
\hline 10 & 3-Ethylphenol & + & - & 24 & 1-Methylnaphthalene & - & + \\
\hline 11 & $\begin{array}{c}\text { 2,4,6-Trimethyl } \\
\text { phenol }\end{array}$ & + & - & 25 & $\begin{array}{l}\text { 1-Methyl-2- } \\
\text { piperidone }\end{array}$ & - & + \\
\hline 12 & $\begin{array}{l}\text { 2-Isopropylphenyl } \\
\text { methylcarbamate }\end{array}$ & + & - & 26 & $\begin{array}{l}\text { 3,5-Dimethyl-2-(2- } \\
\text { methyl-2-propanyl)- } \\
\text { 4-imidazolidinone }\end{array}$ & - & + \\
\hline 13 & $\begin{array}{c}\text { 4-(2-Aminopropy) } \\
\text { phenol }\end{array}$ & + & - & 27 & $\begin{array}{c}\text { 1-(1,3-Thiazol-2-yl) } \\
\text { piperidinone }\end{array}$ & - & + \\
\hline 14 & Benzene & + & - & & & & \\
\hline
\end{tabular}

Note: “+” detected, “ - " not detected. 
Fig. 1 The schematic diagram of VTBR

Fig. 2 Dose-response of coking wastewater on lux bacteria, alga and daphnia

Fig. 3 Swimming behavior changes after exposure to test solutions
(A) Frequency of swimming speed of fish exposed to test solutions $(n=8)$;
(B) Duration time of surfacing behavior of fish $(\mathrm{n}=8)$.

Fig. 4 Acute toxicity units of the influent and effluent for the tested organisms 


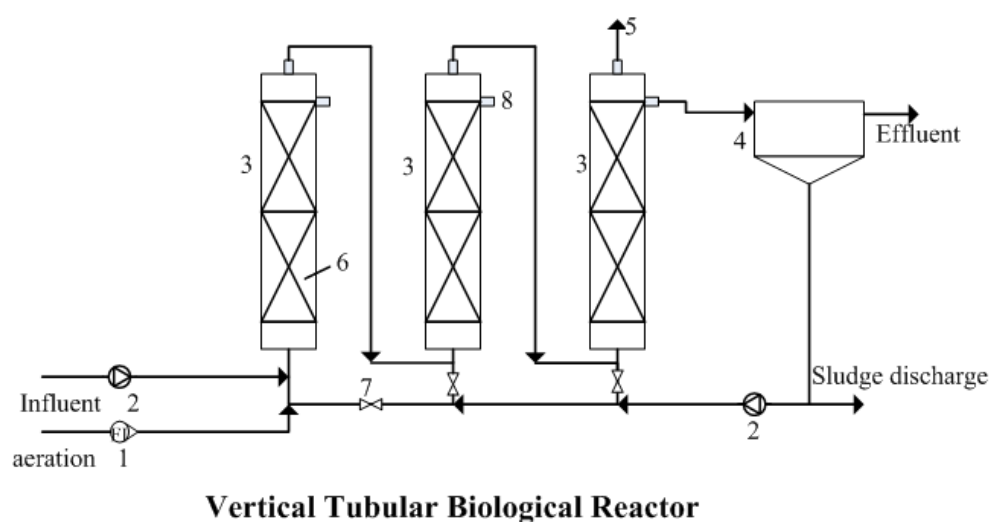

1. glass rotameter(gas) 2. peristatic pump 3. reaction column 4. sedimentation tank 5. exhaust 6. packing 7. valve 8. sampling point 9 . gas diffuser

Fig. 1 The schematic diagram of VTBR 


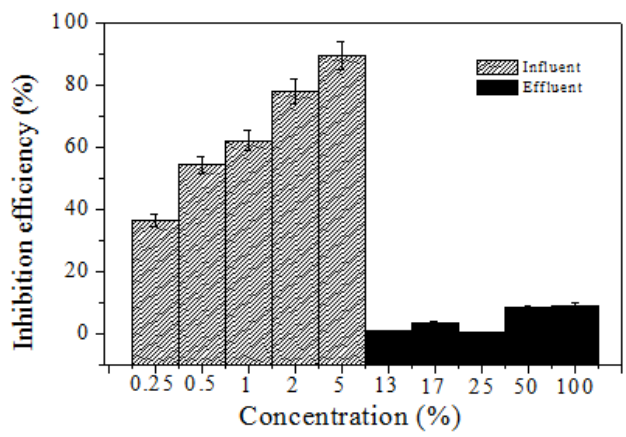

(A)

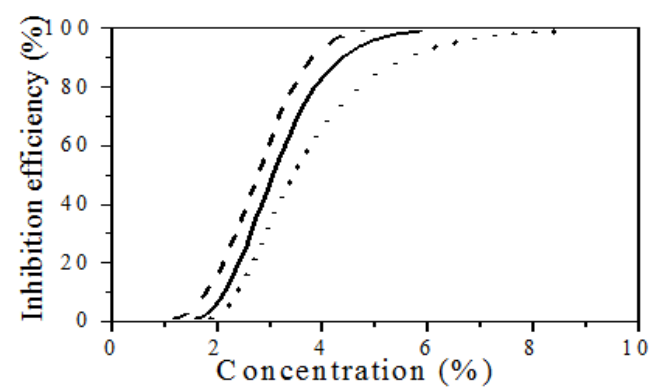

(C)

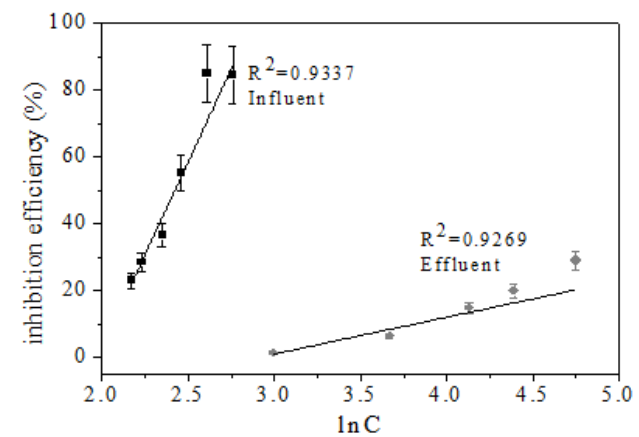

(B)

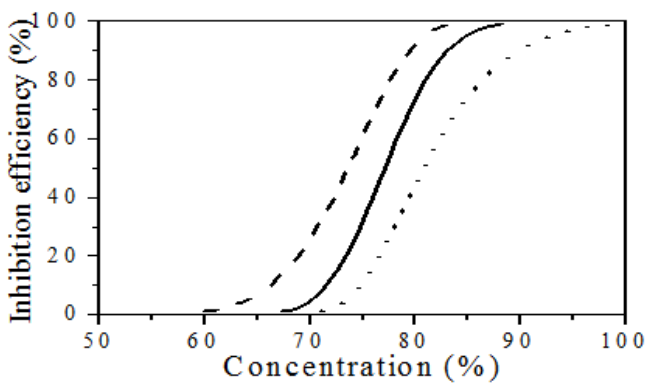

(D)

Fig. 2 Dose-response of coking wastewater on lux bacteria, alga and daphnia (A): Luminous intensity inhibition rate of influent and VTBR effluent on Photobacterium phosphoreum; (B): Dose-response curve on Isochrysis galbana at 96 $\mathrm{h}$; (C) and (D) showed the Dose-response curve of Daphnia magna acute immobilization test (48 h) to influent and effluent of VTBR respectively, the dotted line presents $95 \%$ confidence interval of $48 \mathrm{~h}$ effect concentrations.

Ln C in (B) means the Napierian Logarithm of concentration. 

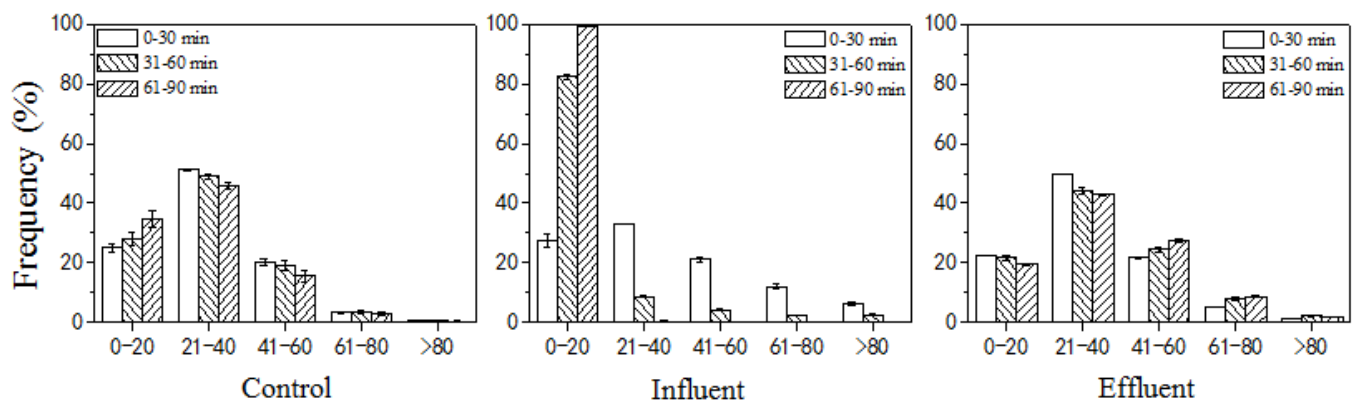

(A) Swimming Speed $(\mathrm{mm} / \mathrm{s})$

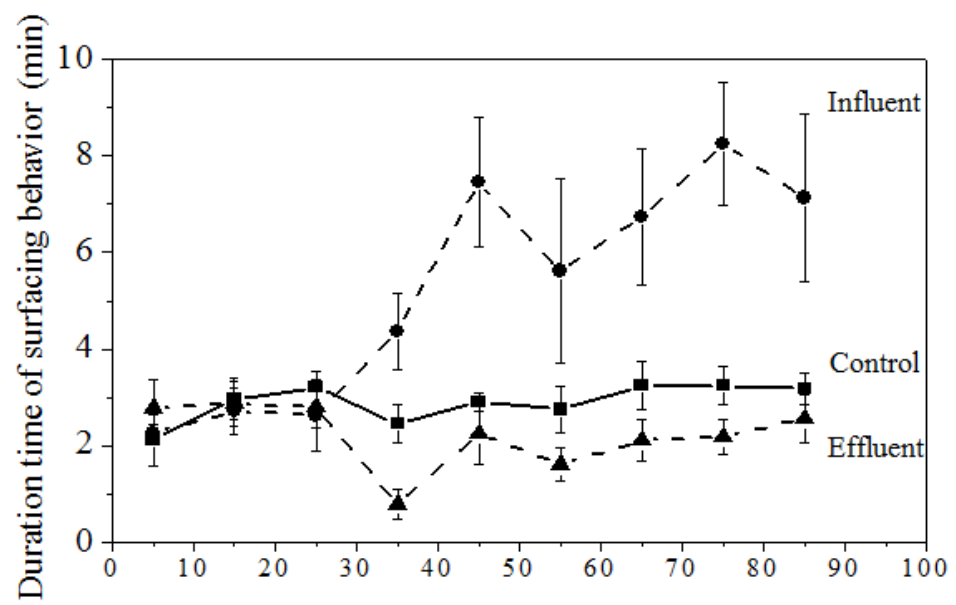

(B) Exposure Time (min)

Fig. 3 Swimming behavior changes after exposure to test solutions

(A) Frequency of swimming speed of fish exposed to test solutions $(n=8)$;

(B) Duration time of surfacing behavior of fish $(\mathrm{n}=8)$. 


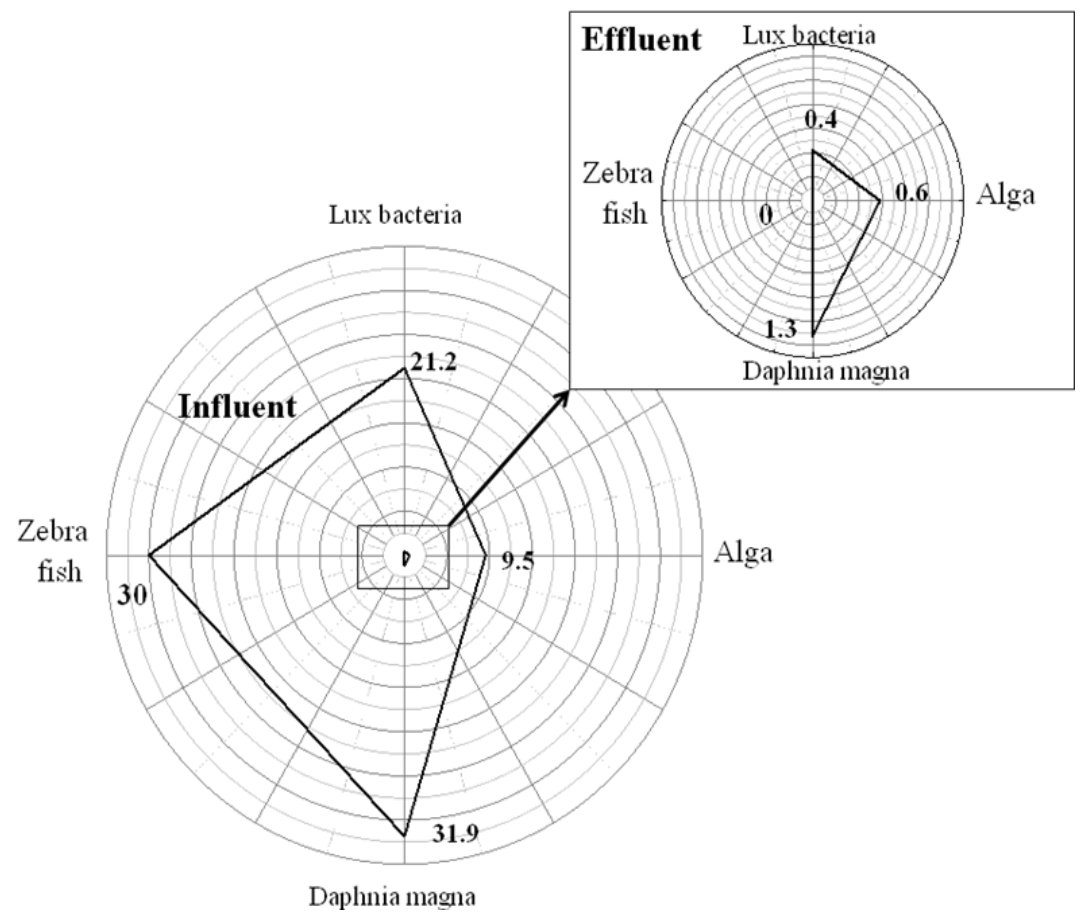

Fig. 4 Acute toxicity units of the influent and effluent for the tested organisms 